\title{
Effect of Relationship Closeness on Group-Induced Choice Shifts Among Chinese Students
}

\author{
Junsu Park \\ Columbia University, New York, USA \\ Do-Yeong Kim 1 \\ Ajou University. South Korea \\ Cheng Cheng \\ China Energy Engineering Group (Guangzhou), China \\ Dongju Lee \\ Washington University, St. Louis, USA
}

\begin{abstract}
Using hypothetical choice-dilemma scenarios, we examined the effect of relationship closeness on group-induced choice shifts in a sample of Chinese college students. Previous studies, which have shown an aversion to risk among Chinese students, have overlooked prior relationship closeness. This study attempts to fill the gap in the research by taking this factor into account. The study found that students shifted their choice toward greater risks when placed in groups composed entirely of individuals with high levels of closeness in their relationships than when they were alone. The implications of the findings are discussed from a Chinese Guanxi cultural perspective.

Keywords: group decision-making, relationship closeness, risky shift, Guanxi.
\end{abstract}

\section{Introduction}

Although evidence of the group-induced risky shift effect (Moscovici \& Zavalloni, 1969) the tendency of groups to shift their choices toward a riskier position than that chosen by the individual members of the groups prior to the discussion - has been consistently detected by studies involving Western student samples (Isenberg, 1986), it seems somewhat puzzling that group contexts have not yielded reliable risky shifts in Chinese student samples. Unlike South Korean students, who exhibited a reliable risky shift regardless of group gender composition (Kim \& Park, 2010), Chinese students either did not take greater risks (Li et al., 2009; Park, Kim, \& Zhang, 2016) or shifted their choices toward caution when making group decisions (Hong, 1978). The authors have explained their findings in terms of the highly influential Confucian doctrine of Zhong Yong (中庸 in Chinese), which emphasizes the avoidance of extremes in the face of two opposing views, not only to reduce in-group conflicts but also to retain harmonious relationships (Yao et al., 2010). Thus, efforts to find an optimal point of compromise between two conflicting views are deemed culturally appropriate, particularly in discussions among group members who are unfamiliar with

1 Corresponding author: School of Business, Ajou University, Suwon, South Korea. E-mail: Do-Yeong Kim kimd@ajou.ac.kr 
each other. Accordingly, these Zhong Yong principles in Chinese Confucian culture are likely to militate against Chinese individuals taking greater risks when making decisions in group situations.

However, the absence of the risky shift in such Chinese samples may not be completely generalizable because the importance of prior relationship closeness among individual members has been overlooked in the group context. This study is designed to fill this gap. We examine the effect of relationship closeness on group decisions involving risk, expecting a significant risky shift to occur in groups of Chinese individuals who have intimate ties with each other. This prediction is derived from the traditional Chinese concept of Guanxi (關係 in Chinese), describing personal ties between two or more parties who treat each other in a manner compatible with social norms, such as escalating reciprocity of personal favors, mutual trust, and affective commitment in a longterm relationship (Chen \& Peng, 2008). Indeed, such norms embedded in Guanxi have been applied to many aspects of Chinese life, such as life satisfaction (Taormina \& Gao, 2010), ethical judgments (Fan et al., 2012), information sharing (Shin et al., 2007), career advancement (Wei et al., 2010), and administrative decisions (Law et al., 2000).

The present study examines whether risky shifts made by groups that consist of three or more best friends with a high level of closeness (i.e., high-Guanxi) differ from the risky shifts of individuals alone (i.e., without group) as well as Strangers with a low level of closeness (i.e., lowGuanxi).

\section{Guanxi as Social Exchange}

As a cultural heritage of lun emphasizing human relationships and social order (King, 1991), Guanxi is viewed as a dynamic process that develops through continued cooperation and repeated exchange of favors, trust, and commitment between both parties to cope with threats from uncertainty (Park \& Luo, 2001) and maintain long-term relationships (Chen \& Chen, 2004). Social exchange theory can provide insights into the dynamics of guanxi exchanges (Blau, 1964; Griffin, 2006; Thibaut \& Kelly, 1959), suggesting that individuals or groups interact for a reward from their interactions with others while expecting to fulfill their obligations to keep the social exchanges in balance. More specifically, if an exchange partner in a horizontal dyad gains a benefit from the other, the receiving partner should feel obliged to reciprocate by paying back the benefit in the future. Although the future exchange of benefits tends to be somewhat unpredictable particularly in the early stage of the relationship due to the risk of non-reciprocation (Whitener et al., 1998), guanxi between two parties continues to develop through the continuous fulfillment of obligations, duties, and indebtedness owed to each other because violating the principle of reciprocity is likely to cause the violators to suffer a serious loss of face and reputation (Lee et al., 2001).

Furthermore, such a reciprocal principle also exists in vertical dyads, such as supervisorsubordinate relationships. Although the interactions between supervisors and subordinates generally begin as a contract-based economic exchange relationship in the Chinese context, they transform into a communal sharing relationship through the familiarization process where supervisors and subordinates share a part of each other's private or family lives by participating in off-the-job activities such as sharing a meal and home visits (Yang, 1992). Through increased personal-life inclusion, supervisors are likely to take care of their subordinates both inside and outside working hours, and in return, the subordinates are also prone to show loyalty, respect, devotion, and deference toward their supervisors (Chen et al., 2009). As a result, guanxi is cultivated when these role obligations based on sentimental ties between the parties are fulfilled, and group harmony will be achieved within the vertical dyads (Hwang, 2012). These reciprocity rules contrast sharply with the Western leader-member exchange (LMX) approach where 
supervisor-subordinate relationships can be converted only into an equity-matching mode; that is, the benefits of work-related support from the supervisor are disproportionally provided to more capable subordinates who achieve enhanced performance (Chen et al., 2009). Chen and Tjosvold (2007) found personal guanxi (resp., LMX) to be effective in helping Chinese employees engage in open-minded discussions with Chinese (resp., American) managers.

Given the salience of Guanxi primacy in relationship-oriented Chinese society, we conjectured that Chinese individuals who feel the great closeness in their relationships cooperate to resolve issues in a way that focuses more on the open-minded debate of opposing views for mutual benefit than on finding the middle as a compromise point when compared to those unfamiliar (Tjosvold \& Yu, 2007). Such an approach helps the former group manage greater risks in groups than as individuals because they are culturally bound by the reciprocal obligations inherent in Guanxi (e.g., continual cooperation and exchange of favors) and thus expect each other to act as a cushion for the possible losses of their risky choices (Hsee \& Weber, 1999). Such social expectations regarding the diffusion of responsibility may allow individual members who share intimate ties to perceive a given situation or issue as less risky (i.e., lower perception of risk - see Sitkin \& Pablo, 1992). Hence, the following hypothesis is proposed:

Hypothesis: Chinese participants are willing to take greater risks when making group decisions with friends to whom they feel close than when making decisions alone.

By adopting a dynamic view that emphasizes the process employing Guanxi-defined as relationship closeness - is initiated, maintained, and undermined (Chen \& Peng, 2008), we can better determine whether the closeness of relationships among Chinese individuals affects their willingness to take risks in group decisions.

\section{Method}

\section{Participants and Design}

A total of 185 . Chinese college students (91 females; age $\mathrm{M}=20.09, \mathrm{SD}=.96$ ) participated in the study in exchange for course credits. The design of this study consisted of three experimental conditions, best friend, stranger, and alone, and a within-subject variable (test: pre and post). Based on the criteria for best-friend relationships found in a preliminary survey, 31 men and 31 women were assigned to two independent same-gender best-friend groups (i.e., 3-4 men [women] per group; 10 groups 2 for each gender), and 30 men and 30 women were assigned to the alone condition (i.e., ten groups for each gender). Two independent same-gender stranger3 groups were also additionally created, consisting of 33 men and 30 women (i.e., eleven 3-male and ten 3-female groups). For the alone and stranger conditions, three men [women] who attended the experiment in the same session were grouped.

\section{Procedure Overview}

Preliminary survey. The survey was distributed randomly to 200 students and completed online using a provided link. All respondents completed the Zhong Yong Thinking Scale (ZYTS) (Wu \& Lin, 2005). Afterward, they were asked to name two or three of their best friends in college and then evaluate the degree of closeness with each of their corresponding nominees. Those who were nominated as best friends by the primary respondents agreed to participate as secondary respondents in the survey and completed the same questionnaires as the primary respondents. Demographic data were then collected from the two respondent groups. 
Park, J.

The best-friend relationship was defined as groups composed entirely of three or more same-gender respondents (i.e., one primary and at least two secondary respondents) who (a) reciprocally nominated each other as best friends and (b) had mean scores of relationship closeness to each other that were more than a chance score of 3 on the closeness scale. Those who met the selection criteria constituted the best-friend condition, while the alone condition refers to those individuals without group and stranger condition that was composed of primary respondents who had either failed to achieve reciprocal nomination or had no best friends in college.

Pre-test. All participants were asked to complete the six hypothetical risk scenarios in the Choice Dilemma Questionnaire (CDQ) individually.

Post-test. The participants in the best-friend and stranger conditions were then given 10 minutes to engage in face-to-face group discussions to reach a group consensus on all six CDQs. The participants in the alone condition responded individually to the same CDQ items again after a 10-minute break.

\section{Measures}

Work Relationship Closeness Scale. We used an adaptation4 of Chen and Peng's (2008) Work Relationship Closeness Scale (WRCS), which was developed while adopting a dynamic view of Guanxi to assess the closeness in Chinese coworker relationships, to evaluate each student respondent's relationship closeness with each of their best-friend nominees. Nine items on this scale were rated on a Likert scale from 1 (completely disagree) to 5 (completely agree); Cronbach's alpha $=.97$.

ZYTS. The ZYTS is a 13-item measures used to assess the tendency to engage in Zhong Yong thinking. Each item was rated on a Likert scale from 1 (strongly disagree) to 5 (strongly agree); Cronbach's alpha $=.94$.

$\boldsymbol{C D Q}$. The level of risk that participants were willing to take under hypothetical situations was assessed using the same set of six items6 from Kogan and Wallach's (1964) 12-item CDQ, as used in a previous study (Kim \& Park, 2010; Park, Kim, \& Zhang, 2016; Ronay \& Kim, 2006). This scale includes six response options-1, 3, 5, 7, or 9 chances in 10 of success and the refusal to accept the risky choice (scored as 10). Lower CDQ scores were interpreted as indicating a preference for greater risk-taking; Cronbach's alpha $=.37$.

\section{Results}

All statistical analyses were conducted on a group basis, because of the interdependence of group members. Table 1 provides descriptive statistics, with "group" as the unit of analysis for each condition.

Manipulation check. A one-sample t-test was used to determine whether WRCS mean scores for the best-friend condition differed from chance. All groups in the best-friend condition scored higher than the chance level of $3, t(19)=8.01, p=10-8$, Cohen's $d=1.81$.

Effect of relationship closeness on group choice. A between-group analysis of covariance controlling for pre-test CDQ scores, ZYTS 9 , and gender was conducted with conditions as a predictor and the post-test CDQ score as the dependent variable to determine the effect of relationship closeness on group choice.

There was a significant effect of pre-test CDQ score, $F(1,55)=87.03, p=10-13, \eta^{2}=.61$, indicating that the individual group members' aggregated preference for risk affected group choice after discussion. No effects of ZYTS, $F(1,55)=1.92, p=.17, \eta_{2}=.03$, or gender, $F(1,55)=.86$, 
$p=.36, \eta_{2}=.02$, were found, but there was a significant main condition effect $10, F(2,55)=7.26$, $p=10-3, \eta_{2}=.21$. The participants in the best-friend condition expressed a riskier position in posttest CDQ scores than those in the stranger, $t(55)=2.36, p=.02, d=.74$, and alone, $t(55)=3.77$, $p=10-4, d=.73$, conditions. This difference was not noted between the stranger and alone conditions, $t(55)=1.42, p=.16, d=.12$.

Table 1

Descriptive Statistics for all Variables by Condition

\begin{tabular}{ccccccc}
\hline \multirow{2}{*}{ Measures } & \multicolumn{2}{c}{ Best friend $(N=20)$} & \multicolumn{2}{c}{ Alone $(N=20)$} & \multicolumn{2}{c}{ Stranger $(N=21)$} \\
\cline { 2 - 7 } & Pre-test & Post-test & Pre-test & Post-test & Pre-test & Post-test \\
\hline \multirow{2}{*}{ CDQ } & 36.09 & 31.25 & 35.63 & 36.00 & 38.10 & 36.71 \\
& $(5.40)$ & $(7.97)$ & $(4.43)$ & $(4.53)$ & $(4.83)$ & $(6.79)$ \\
ZYTS & $3.64(.58)$ & & $3.85(.62)$ & & $3.88(.50)$ & \\
WRCS & $3.96(.53)$ & & & & & \\
\hline
\end{tabular}

Note. Values are denoted as $M(S D)$.

Taking the nested nature of our data into account, a hierarchical linear modeling analysis was conducted to determine the amount of variance in the post-test CDQ scores that could be explained by individual-level and group-level variables. Results showed the same pattern as that detected in the ANCOVA described above (Online Supplemental Table 6).

Influence of relationship closeness on choice shift. A hierarchical regression analysis was performed to examine whether the closeness of relationships among the participants in the bestfriend condition affected their choice shift. Step one included gender and ZYTS as covariates, which did not account for the variance in the dependent variable (i.e., pre-test minus post-test CDQ group mean scores), $F(2,17)=1.16, p=.34$. Inclusion of the WRCS 11 as a predictor resulted in an $R 2$ change of $.05, F(1,16)=4.43, p=.05$ (step two), indicating the influence of relationship closeness to be positively significant, $\beta=.45$.

\section{Discussion and Implications}

Previous cross-national studies of the risky shift phenomenon have focused largely on groups comprising Chinese individuals unfamiliar with each other and have reported a reliable pattern reflecting the absence of group-induced risky shift (Hong, 1978; Li et al., 2009; Park et al., 2016). In this article, we focused on groups comprising Chinese students who named each other reciprocally as best friends and found that the risky shift manifests itself, at least in cases where personal relations among group members are defined as being very close. Our findings can be interpreted by drawing on social identity theory (Ellemers et al., 2002; Tajfel, 1982). In Chinese society, guanxi plays a key role in developing an in-group identity among guanxi-connected members, a sense of belonging from their membership in groups, and perceived insider status, which is the sources of personalized trust owed to in-groups (Hwang, 1999; House et al., 1997), thereby eliciting from Chinese individuals in a guanxi web to feel well-prepared to accept vulnerability by taking greater risk in group choices based on their mutual trust that in-group members will reciprocate for past benefits received when in trouble to assure themselves of continued benefits from each other (Han et al., 2012). 
However, this interpretation is limited to the Chinese context. Further studies are required with larger samples drawn from collectivist and individualist cultures to determine whether the present findings are China-specific or universally observed phenomena while controlling for potentially confounding factors such as negative feelings after a disagreement with close friends. An attempt in this direction was recently made, examining collectivist-bound students in South Korea (Park, Kim, Lee, \& Lee, 2016), indicating the absence of group-induced risky shift when personal relations among group members are intertwined with closeness.

Another approach to advancing the relationship literature would be to test whether the way risk is handled features exceptions in relationship types. Research on family businesses provides supporting evidence for this, indicating that family firms take fewer risks than do non-family firms because of concerns about the safety of the family's wealth (Naldi et al., 2007). These findings suggest that Chinese individuals may be reluctant to take greater risks when making decisions with family members because mutual favors and commitments in family-level relationships can be exchanged in a way that secures their in-group members against the responsibility for possible losses caused by the risky option (e.g., the financial burden of failed investments)

By demonstrating that the risky shift occurs particularly when Chinese participants are involved in a group context that reflects the salience of relationship closeness among members, our study contributes by stimulating discussion about how the group-induced risky shift phenomenon can be characterized by the quality of relationships with friends, coworkers, and family members, at least in the Chinese cultural context.

\section{Notes}

1. We based the sample size on prior research (Park, Kim, \& Zhang, 2016).

2. One group from each gender consisted of four participants because they reciprocally nominated each other as best friends.

3. Further information on the research design and materials involved in the stranger condition can be found in Online Supplementary Table 1.

4. We used a slightly modified version of the WRCS (see Online Supplementary Table 2), replacing the phrase "at work" with the phrase "at college" to measure students' relationship closeness with their best friends in college.

5. The 13-item scale can be seen in Online Supplementary Table 3.

6. The 6-item scale can be seen in Online Supplementary Table 4.

7. The low reliability of the CDQ has been consistently reported not only in early research (range: .53 to .80; Wallach et al., 1962) but also in recent studies (range: 40 to .60; Kim \& Park, 2010; Park et al., 2016; Ronay \& Kim, 2006). This suggests that the perception of risk inherent in each choice dilemma may differ because of individual differences.

8. According to group polarization, group choice at post-test tended to be more extreme (risky or cautious) in the same direction as the average of the choices of individual members at pre-test; our data support this argument. In fact, pre-test and post-test CDQ group mean scores were found to be positively correlated across conditions, $r=.78, p=10-5$ for best friend; $r=.76, p=$ 10-5 for stranger; $r=.89, p=10-7$ for alone. Thus, the pre-test CDQ score at the group level was included in the analysis.

9. Because the ZYTS was collected at an individual level, the responses were aggregated to a group-level analysis by averaging across the participants who were grouped. This aggregation was justified because the average $r_{w g}$ for all groups was greater than .70 (i.e., .74 in this study; James et al., 1984). 
10. We also analyzed the individual CDQ items and have reported these results in Online Supplementary Table 5.

11. On the WRCS, the average $r_{w g}$ for all groups in the best-friend condition was .90 .

\section{Funding Details}

This work was supported by a grant funded by the Ministry of Education and the National Research Foundation of Korea (NRF-2016S1A5A2A01025621) awarded to Do-Yeong Kim.

\section{Disclosure Statement}

All authors declare that they have no conflict of interest.

\section{References}

Blau, P. M. (1964). Exchange and power in social life. Jossy-Bass.

Chen, N. Y. F., \& Tjosvold, D. (2007). Guanxi and leader member relationships between American managers and Chinese employees: Open-minded dialogue as mediator. Asia Pacific Journal of Management, 24(2), 171-189. https://doi.org/10.1007/s10490-006-9029-9

Chen, X. P., \& Peng, S. (2008). Guanxi dynamics: Shifts in the closeness of ties between Chinese coworkers. Management and Organization Review, 4(1), 63-80. https://doi.org/10.1111/j.1740-8784.2007.00078.x

Chen, Y., Friedman, R., Yu, E., Fang, W., \& Lu, X. (2009). Supervisor-subordinate Guanxi: Developing a three-dimensional model and scale. Management and Organization Review, 5(3), 375-399. https://doi.org/10.1111/j.1740 8784.2009.00153.x

Ellemers, N., Spears, R., \& Doosje, B. (2002). Self and social identity. Annual Review of Psychology, 53(1), 161-186. https://doi.org/10.1146/annurev.psych.53.100901.135228

Fan, Y. H., Woodbine, G., \& Scully, G. (2012). Guanxi and its influence on the judgments of Chinese auditors. Asia Pacific Business Review, 18(1), 83-97. https://doi.org/10.1080/13602381.2010.550124

Griffin, E. M. (2006). A first look at communication theory. McGraw-Hill.

Han, Y., Peng, Z., \& Zhu, Y. (2012). Supervisor-subordinate guanxi and trust in supervisor: A qualitative inquiry in the People's Republic of China. Journal of Business Ethics, 108(3), 313-324. https://doi.org/10.1007/s10551-011-1092-6

House, R. J., Wright, N. S., \& Aditya, R. N. (1997). Cross-cultural research on organizational leadership: A critical analysis and a proposed theory. In P. C. Earley, \& M. Erez (Eds.), New perspectives on international industrial/organizational psychology (pp. 535-625). The New Lexington Press.

Hsee, C. K., \& Weber, E. U. (1999). Cross-national differences in risk preference and lay predictions. Journal of Behavioral Decision Making, 12(2), 165-179. https://ssrn.com/abstract=930081

Hwang, K. K. (1999). Filial piety and loyalty: Two types of social identification in Confucianism. Asian Journal of Social Psychology,2(1), 163-183. https://doi.org/10.1111/1467-839X.00031

Hwang, K. K. (2012). The deep structure of confucianism. In K.-K. Hwang (Ed.), Foundations of Chinese psychology: Confucian social relations, 99-131. Springer. 
Park, J.

Isenberg, D. J. (1986). Group polarization: A critical review and meta-analysis. Journal of Personality and Social Psychology, 50(6), 1141-1151. https://doi.org/10.1037/00223514.50.6.1141

James, L. R., Demaree, R. G., \& Wolf, G. (1984). Estimating within-group interrater reliability with and without response bias. Journal of Applied Psychology, 69(1), 85-98. https://doi.org/10.1037/0021-9010.69.1.85

Kim, D-Y., \& Park, J. (2010). Cultural differences in risk: The group facilitation effect. Judgment and Decision Making, 5(5), 380-390.

King, A. Y. C. (1991). Kuan-hsi and network building: A sociological interpretation. Daedalus, 120(2), 63-84.

Kogan, N., \& Wallach, M. A. (1964). Risk-taking: A study in cognition and personality. Holt, Rinehart \& Winston.

Law, K. S., Wong, C. S., Wang, D. X., \& Wang, L. H. (2000). Effect of supervisor - subordinate guanxi on supervisory decisions in China: An empirical investigation. International Journal of Human Resource Management, 11(4), 751-765. https://doi.org/10.1080/09585190050075105

Li, S., Bi, Y. L., \& Zhang, Y. (2009). Asian risk seeking and overconfidence. Journal of Applied Social Psychology, 39(11), 2706-2736. https://doi.org/10.1111/j.1559-1816.2009.00545.x

Moscovici, S., \& Zavalloni, M. (1969). The group as a polarizer of attitudes. Journal of Personality and Social Psychology, 12(2), 125-135. https://doi.org/10.1037/h0027568

Naldi, L., Nordqvist, M., Sjöberg, K., \& Wiklund, J. (2007). Entrepreneurial orientation, risk taking, and performance in family firms. Family Business Review, 20(1), 33-47. https://doi.org/10.1111/j.1741-6248.2007.00082.x

Park, J., Kim, D-Y., \& Zhang, C. (2016). Understanding cross-national differences in risk through a localized cultural perspective. Cross-Cultural Research,50(1), 34-62. https://doi.org/10.1177/1069397115609560

Park, J., Kim, D-Y., Lee, O., \& Lee, D. J. (2016, August 4-7). A national comparison of Guanxi effect on group decision making under risk: China vs. South Korea [Paper presentation]. Annual Convention of American Psychological Association, Denver, CO.

Ronay, R., \& Kim, D-Y. (2006). Gender differences in explicit and implicit risk attitudes: A socially facilitated phenomenon. British Journal of Social Psychology, 45(2), 397-419. https://doi.org/10.1348/014466605X66420

Shin, S. K., Ishman, M., \& Sanders, G. L. (2007). An empirical investigation of socio-cultural factors of information sharing in China. Information \& Management, 44(2), 165-174. https://doi.org/10.1016/j.im.2006.11.004

Sitkin, S. B., \& Pablo, A. L. (1992). Reconceptualizing the determinants of risk behavior. Academy of Management Review, 17(1), 9-38. https://doi.org/10.5465/amr.1992.4279564

Tajfel, H. (1982). Social identity and intergroup relations. Cambridge University Press.

Taormina, R. J., \& Gao, J. H. (2010). A research model for Guanxi behavior: Antecedents, measures, and outcomes of Chinese social networking. Social Science Research, 39(6), 1195-1212. https://doi.org/10.1016/j.ssresearch.2010.07.003

Thibaut, J., \& Kelly, H. (1959). Social Exchange Theory. In E. Griffin, (Ed.), A first look at a communication theory. McGraw-Hill.

Tjosvold, D., \& Yu, Z. (2007). Group risk-taking: The constructive role of controversy in China. Group \& Organization Management, 32(6), 653-674. https://doi.org/10.1177/1059601106287110 
Wallach, M. A., Kogan, N., \& Bem, D. J. (1962). Group influence on individual risk-taking. Journal of Abnormal and Social Psychology, 65(2), 75-86. https://doi.org/10.1037/h0044376

Wei, L. Q., Liu, J., Chen, Y. Y., \& Wu, L. Z. (2010). Political skill, supervisor-subordinate guanxi and career prospects in Chinese firms. Journal of Management Studies, 47(3), 437-454. https://doi.org/10.1111/j.1467-6486.2009.00871.x

Whitener, E. M., Brodt, S. E., Korsgaard, M. A., \& Werner, J. M. (1998). Managers as initiators of trust: An exchange relationship framework for understanding managerial trustworthy behavior. Academy of Management Review, 23(3), 513-530. https://doi.org/10.5465/amr.1998.926624

Wu, C. H., \& Lin, Y. C. (2005). Development of a Zhong-Yong thinking style scale. Indigenous Psychological Research in Chinese Societies, 24, 247-300.

Yang, K. S. (1992). Chinese social orientation: From the social interaction perspective. In K. S. Yang \& A. B. Yu (Eds.), Chinese Psychology and Behavior, 87-142. Laurel.

Yao, X., Yang, Q., Dong, N., \& Wang, L. (2010). Moderating effect of Zhong Yong on the relationship between creativity and innovation behaviour. Asian Journal of Social Psychology, 13(1), 53-57. https://doi.org/10.1111/j.1467-839X.2010.01300.x 